Published in final edited form as:

J Am Chem Soc. 2016 March 16; 138(10): 3310-3313. doi:10.1021/jacs.6b01445.

\title{
Rhodium-Catalyzed Enantioselective Cycloisomerization to Cyclohexenes Bearing Quaternary Carbon Centers
}

\author{
Jung-Woo Park, Zhiwei Chen, and Vy M. Dong* \\ Department of Chemistry, University of California, Irvine, 4403 Natural Sciences 1, Irvine, \\ California 92697, United States
}

\begin{abstract}
We report a Rh-catalyzed enantioselective cycloisomerization of a, $\omega$-heptadienes to afford cyclohexenes bearing quaternary carbon centers. Rhodium(I) and a new SDP ligand promote chemoselective formation of a cyclohex-3-enecarbaldehyde motif that is inaccessible by the DielsAlder cycloaddition. Various a,a-bisallylaldehydes rearrange to generate six-membered rings by a mechanism triggered by aldehyde $\mathrm{C}-\mathrm{H}$ bond activation. Mechanistic studies suggest a pathway involving regioselective carbometallation and endocyclic $\beta$-hydride elimination.
\end{abstract}

\section{TOC graphic}

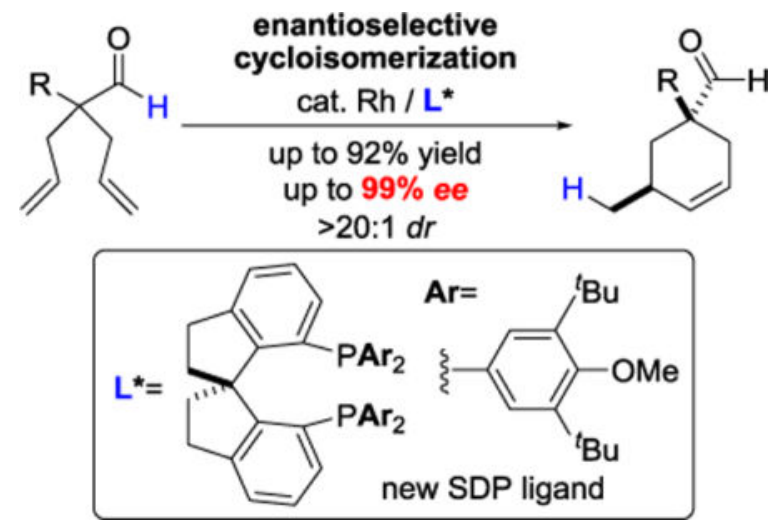

The cycloisomerization of dienes represents a powerful and atom-economical route to unsaturated carbocycles that remains relatively limited to the preparation of five-membered rings (Figure 1a). ${ }^{1,2}$ Cycloisomerizations to six-membered rings have been challenging to achieve with high regio- and enantiocontrol. ${ }^{1-4}$ Such strategies remain sought after due to the need for cyclohexenes as building blocks and their common occurrence in nature. ${ }^{5}$ Inspired by natural products, including pinnatal, jerantiphylline A, and myricolal (Figure 1b), ${ }^{6}$ we designed a metal-catalyzed isomerization to generate cyclohex-3-enecarbaldehydes

Corresponding Author:dongv@uci.edu.

Supporting Information

Experimental procedures and spectral data for all new compounds. This material is available free of charge via the Internet at http:// pubs.acs.org.

Notes

The authors declare no competing financial interests. 
bearing a-quaternary centers. ${ }^{7}$ Herein, we disclose a desymmetrization of bisallylaldehydes 1 to generate cyclohexenes $\mathbf{4}$ via the desymmetrization of prochiral quaternary centers (Figure 1c-route A). ${ }^{7-10}$ Our Rh-catalyzed method provides enantioselective access to the 3,5,5-trisubstituted cyclohexene motif that is inaccessible by the well-established DielsAlder reaction and therefore complements conventional cycloadditions (Figure 1d). ${ }^{11}$

The initial steps of our proposal rely on the well-precedented hydroacylation mechanism, namely aldehyde $\mathrm{C}-\mathrm{H}$ bond activation and olefin insertion, ${ }^{12,13}$ to form intermediate 2 (Figure 1c). Next, we imagined that a regioselective carbometallation of the pendant olefin could afford 3, which upon endocyclic $\beta$-hydride elimination ${ }^{13,14}$ would lead to the unprecedented cyclohexene 4 (Figure 1c-route A). Carbometallation could occur with the opposite regioselectivity to generate $\mathbf{5}$, which upon reductive elimination would yield bicyclic heptanones 6 (Figure 1c-route B). ${ }^{15 a}$ On the basis of our previous study, ${ }^{13}$ we realized that the key challenge would be to identify a catalyst to favor the proposed cycloisomerization, in preference to the known hydroacylation and carboacylation ${ }^{15}$ pathways.

With this hypothesis in mind, we chose 2-allyl-2-benzylpent-4-enal (1a) as a model substrate for desymmetrization (Chart 1). In general, electron-donating bidentate phosphine ligands with bite-angles ranging from $89-91^{\circ}$ favored formation of the cyclopentanone 8a via isomerization-hydroacylation pathways. ${ }^{13,16}$ By focusing on ligands with bite-angles ranging from $96-100^{\circ},{ }^{16}$ we discovered two ligand classes that resulted in formation of cyclohexenes $4 \mathbf{a} / 7 \mathbf{a}^{17}$ and bicyclic heptanone $6 \mathbf{a}$ via the carbometallation pathway. By tuning the aryl-substituents on DPPF, we observed a modest increase in selectivity for the generation of cyclohexenes.

Zhou's rigid spiro-bisphosphine ligand, $(S)$-Ph-SDP, ${ }^{18}$ gave the most promising lead as we obtained cyclohex-3-enecarbaldehyde $4 \mathbf{a}$ in $71 \%$ yield as the major product (99\% ee, >20:1 $d r$ ) with generation of $\mathbf{6 a}$ in $23 \%$ yield. Transformation of $\mathbf{1 a}$ with Rh-SDP catalyst was efficient with $2.5 \mathrm{~mol} \%$ catalyst loading. By fine-tuning the aryl-substituents on the Zhou ligand, we observed a dramatic effect on the selectivity for $4 \mathbf{a}$ over $\mathbf{6 a}$. Commercially available (S)-Ph-SDP and (S)-Xyl-SDP showed similar ca. 3:1 selectivity for 4a over 6a. By changing the meta-substituents on the phenyl group from methyl to $t$-butyl ((S)-DTB-SDP), we observed $\mathbf{4 a}$ as the predominant product. There was a drop in enantioselectivity from $96 \%$ ee to $83 \%$ ee. We prepared a novel analogue, $(R)$-DTBM-SDP, which bears an additional para-methoxy substituent. This designer ligand gave $\mathbf{4 a}$ as the major product, with high enantioselectivity and diastereoselectivity $(95 \% e e,>20: 1 \mathrm{dr})$.

Next, we used this protocol to prepare cyclohex-3-enecarbaldehydes bearing a-quaternary stereocenters (Table 1). Aldehydes with a-aliphatic substituents (1a-1j) underwent cycloisomerization in 71-92\% yields with high enantioselectivities and diastereoselectivities (up to 98\% ee, >20:1 dr). Cyclopropyl groups (1e), nitrogen heterocycles (1d and 1g), haloaromatics $(\mathbf{1 d})$, ethers $(\mathbf{1 b}, \mathbf{1} \mathbf{i}$, and $\mathbf{1 j}$ ), and ketones $(\mathbf{1} \mathbf{j})$ were well-tolerated under these conditions. 
Aldehydes bearing more sterically encumbered a-substituents such as cyclohexyl (1k) and aromatic groups (1)-q) were challenging to cyclize. However, by using Ph-SDP as the ligand and applying a higher rhodium loading (5\%), we obtained the corresponding cyclohexenecarbaldehydes (4k $\mathbf{k}$ and $\mathbf{4 l}-\mathbf{q}$ ) as the major products (about 2:1 chemoselectivity $(\mathbf{4} /(\mathbf{6}+\mathbf{8})), 54-68 \%$ isolated yields, and 96-99\% ee's). Aldehyde 1r, bearing the 1-naphthyl group, was unreactive with DTBM-SDP as the ligand, but could be cycloisomerized using the less bulky ligand, Tol-SDP. The aldehyde bearing a $\beta$-benzyloxy group $(\mathbf{1 s})$ transformed to the cyclohexene in only $35 \%$ yield because the $\gamma$-oxygen directing group promotes hydroacylation over cycloisomerization. ${ }^{13,14}$ No reactivity was observed with more hindered, substituted olefin substrates. ${ }^{19}$ While further catalyst development is warranted, our study represents a rare example of isomerization of $\alpha, \omega$-heptadienes to generate cyclohexenes with high enantiocontrol.

Aldehydes $\mathbf{4}$ can be easily oxidized or reduced to generate the corresponding acids or alcohols, respectively (Scheme 1). Depending on its oxidation state, the resulting cyclohexenes can undergo a number of selective transformations. For example, the aldehyde is necessary to initiate isomerization of the olefin to generate cyclohexenecarbaldehyde 7a using a Rh(I)/dppf complex (Scheme 1a). ${ }^{20}$ Subjecting ester 9 to the same reaction conditions resulted in no isomerization of the olefin (Scheme 1b). From this observation, we believe isomerization is triggered by aldehyde $\mathrm{C}-\mathrm{H}$ bond activation, which generates the requisite Rh-hydride. ${ }^{13,14,21}$ By Pinnick oxidation ${ }^{22}$ of $\mathbf{4 a}$, we obtained the carboxylic acid derivative 10. Iodolactonization of cyclohex-3-enecarboxylic acid $\mathbf{1 0}$ afforded [3.2.1]bicyclic lactone $\mathbf{1 1}$ containing four stereogenic centers as a single regio- and diastereomer (Scheme 1c). Reduction of the aldehyde $\mathbf{4 a}$ to the alcohol resulted in $\mathbf{4 a - O H}$. The alcohol can be used to direct a diastereoselective cyclopropanation to form bicycloheptane $\mathbf{1 2}$ (Scheme 1d, $d r>20: 1$ ). Alcohol $\mathbf{4 m - O H}$ can be acylated to generate ester $\mathbf{1 3}$ or sulfamylated to give sulfamate 14. The molecular structure and absolute configuration of $\mathbf{1 3}$ was determined by X-ray crystallography (Scheme 1e) ${ }^{23}$ By using White's protocol, sulfamate $\mathbf{1 4}$ can undergo a highly diastereoselective allylic $\mathrm{C}-\mathrm{H}$ bond amination to afford $\mathbf{1 5}$ (Scheme 1f). ${ }^{24}$ These simple derivatizations allow a number of different cyclohexanes and cyclohexenes to be prepared with substitution patterns that would otherwise be difficult to access.

On the basis of our observations and literature precedence, we propose the mechanism shown in Scheme 2. The cationic $\mathrm{Rh}(\mathrm{I})$-complex activates the aldehyde $\mathrm{C}-\mathrm{H}$ bond of $\mathbf{1}$ to form acyl-Rh(III)-hydride $\mathbf{1 6}$ which undergoes hydrometallation to generate rhodacycle $\mathbf{2}$. Carbometallation onto the pendant olefin in rhodacycle 2 can occur to afford carbometallated intermediate $\mathbf{3}$, which would then undergo $\beta$-hydride elimination to form acyl-Rh(III)-hydride 17. Reductive elimination from 17 leads to formation of cycloisomerization product 4 . Reductive elimination from $\mathbf{2}$ or $\mathbf{3}$ would result in formation of a strained cyclobutanone, which is not observed. The carbometallation of rhodacycle 2 onto the pendant olefin with opposite regioselectivity would result in rhodabicycle 5 (Figure 1c), which undergoes reductive elimination to form 6. 
Our study reveals that the bite angle of the ligand is critical for promoting carboacylation in preference to isomerization-hydroacylation pathways. An electron-donating MeOBiphep ligand (bite angle: $90.6^{\circ}$ ) enables an enantioselective hydroacylation to afford cyclopentanone 8. ${ }^{13}$ Phosphine ligands with bite angles ranging from $96-99^{\circ}$ promote formation of bicyclic heptanone $6{ }^{13}$ Yet, the rigid spiro-bisphosphine ligand, $(S)$-Ph-SDP (bite angle: $96.2^{\circ}$ ) favors a different carbometallation that leads to cyclohexene 4 .

To gain insight into the mechanism, we performed a deuterium-labeling study with $d-\mathbf{1 a}$. The reaction of $d-\mathbf{1} \mathbf{a}$, under standard reaction conditions, led to formation of $d-\mathbf{4 a} \mathbf{a}$ where $80 \%$ of the deuterium label was incorporated into the 5-methyl group and $20 \%$ was scrambled between the aldehyde and the 4-position (eq 1). This deuterium scrambling suggests that the olefin-insertion step $(\mathbf{1 6} \rightarrow \mathbf{2}$ in Scheme 2) is reversible. As a result, either carbometallation or $\beta$-hydride elimination is the rate- and enantiodetermining step.

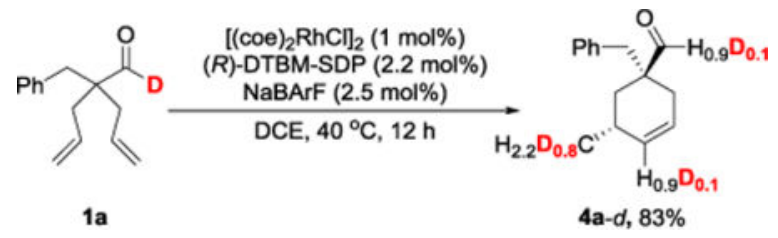

We have demonstrated a Rh-catalyzed enantioselective cycloisomerization of a,abisallylaldehydes to form cyclohex-3-enecarbaldehydes. These products represent versatile intermediates that can be elaborated to a range of structures. Mechanistic studies support an aldehyde-assisted cycloisomerization followed by a regioselective carbometallation. The use of a novel SDP ligand enables high selectivity for cycloisomerization. Further experimental and theoretical studies are underway to elucidate the origin of chemoselectivity and guide development of other cycloisomerizations.

\section{Supplementary Material}

Refer to Web version on PubMed Central for supplementary material.

\section{Acknowledgments}

Funding provided by UC Irvine and the National Institutes of Health (GM105938). We are grateful to Eli Lilly for a Grantee Award. We thank Dr. Joseph W. Ziller and Mr. Jason R. Jones for X-ray crystallographic analysis.

\section{References}

1.

For recent reviews, see:

(a) Yamamoto Y. Chem Rev. 2012; 112:4736. [PubMed: 22703601] (b) Aïssa C. Synlett. 2014; 25:2379.

For a seminal review of cycloisomerization, see:

(c) Trost BM, Krische MJ. Synlett. 1998; 1 
2. Watson IDG, Toste FD. Chem Sci. 2012; 3:2899.

3. (a) Molander GA, Hoberg JO. J Am Chem Soc. 1992; 114:3123.(b) Negishi, E-i; Jensen, MD.; Kondakov, DY.; Wang, SJ. Am Chem Soc. 1994; 116:8404.(c) Radetich B, RajanBabu TV. J Am Chem Soc. 1998; 120:8007.(d) Grau F, Heumann A, Duñach E. Angew Chem Int Ed. 2006; 45:7285.

4.

For rare examples of enantioselective cycloisomerizations to six-membered rings using $\omega$-indolylalkene and $a, \omega$-enallene, see

(a) Han X, Widenhoefer RA. Org Lett. 2006; 8:3801. [PubMed: 16898821] (b) Tarselli MA, Chianese AR, Lee SJ, Gargné MR. Angew Chem Int Ed. 2007; 46:6670.

5. (a) Sato K, Aoki M, Noyori R. Science. 1998; 281:1646. [PubMed: 9733504] (b) He W, Fang Z, Tian Q, Shen W, Guo K. Ind Eng Chem Res. 2016; 55:1373.

6.

For pinnatal:

(a) Malerich JP, Trauner DJ. Am Chem Soc. 2003; 125:9554.

For jerantiphylline A:

(b) Lim K-H, Thomas NF, Abdullah Z, Kam T-S. Phytochem. 2009; 70:424.

For myricolal:

(c) Yaguchi Y, Sakurai N, Nagai M, Inoue T. Chem Pharm Bull. 1988; 36:1419.

7.

For reviews on enantioselective construction of quaternary stereocenters, including desymmetrization strategies, see:

(a) Quasdorf KW, Overman LE. Nature. 2014; 516:181. [PubMed: 25503231] (b) Douglas CJ, Overman LE. Proc Natl Acad Sci USA. 2004; 101:5363. [PubMed: 14724294] (c) Liu Y, Han SJ, Liu W-B, Stoltz BM. Acc Chem Res. 2015; 48:740. [PubMed: 25715056] (d) Lebel H, Marcoux JF, Molinaro C, Charette AB. Chem Rev. 2003; 103:977. [PubMed: 12683775] (e) Petersen KS. Tetrahedron Lett. 2015; 56:6523. [PubMed: 26834295]

8.

For select examples of using carbenoids to set quaternary stereocenters, see:

(a) Briones JF, Davies HML. J Am Chem Soc. 2013; 135:13314. [PubMed: 23978108] (b) Spangler JE, Davies HML. J Am Chem Soc. 2013; 135:6802. [PubMed: 23607705] (c) Hyster TK, Ruhl KE, Rovis TJ. Am Chem Soc. 2013; 135:5364.

9.

For recent desymmetrizations of quaternary stereocenters, see:

(a) Zhou F, Cheng G-J, Yang W, Long Y, Zhang S, Wu Y-D, Zhang X, Cai Q. Angew Chem Int Ed. 2014; 53:9555.(b) Roux C, Candy M, Pons J-M, Chuzel O, Bressy C. Angew Chem Int Ed. 2014; 53:766.(c) Yao L, Liu K, Tao H-Y, Qiu G-F, Zhou X, Wang C-J. Chem Commun. 2013; 49:6078.(d) Lee JY, You YS, Kang SH. J Am Chem Soc. 2011; 133:1772. [PubMed: 21265528] 10.

For desymmetrizations involving $\mathrm{C}-\mathrm{H}$ activation, see:

(a) Phan DHT, Kou KGM, Dong VMJ. Am Chem Soc. 2010; 132:16354.(b) Xiao K-J, Lin DW, Miura M, Zhu R-Y, Gong W, Wasa M, Yu J-Q. J Am Chem Soc. 2014; 136:8138. [PubMed: 24815880] (c) Shi B-F, Zhang Y-H, Lam JK, Wang D-H, Yu J-Q. J Am Chem Soc. 2010; 132:460. [PubMed: 20017549]

J Am Chem Soc. Author manuscript; available in PMC 2017 March 16. 
11. (a) Carey, FA.; Sundberg, RJ. Advanced Organic Chemistry Part A: Structure and Mechanisms. 5th. NY: Springer; 2007. p. 843-848.(b) Huang Y, Iwama T, Rawal VH. J Am Chem Soc. 2000; 122:7843.

12. (a) Willis MC. Chem Rev. 2010; 110:725. [PubMed: 19873977] (b) Park YJ, Park J-W, Jun C-H. Acc Chem Res. 2008; 47:109.

13. Park J-W, Kou KGM, Kim DK, Dong VM. Chem Sci. 2015; 6:4479. [PubMed: 26508999]

14. Yip SYY, Aïssa C. Angew Chem Int Ed. 2015; 54:6870.

15.

For a related carbocyclization using pyridyl directing groups, see:

(a) Aïssa C, Ho KYT, Tetlow DJ, Pin-Nó M. Angew Chem Int Ed. 2014; 53:4209.

For recent Rh-catalyzed carboacylations, see:

(b) Ko HM, Dong G. Nature Chem. 2014; 6:739. [PubMed: 25054946] (c) Souillart L, Cramer N. Angew Chem Int Ed. 2014; 53:9640.(d) Souillart L, Parker E, Cramer N. Angew Chem Int Ed. 2014; 53:3001.(e) Xu T, Ko HM, Savage N, Dong G. J Am Chem Soc. 2012; 134:20005.

[PubMed: 23171396] (f) Dreis AM, Douglas CJ. J Am Chem Soc. 2009; 131:412. [PubMed: 19105696]

16. (a) Freixa Z, van Leeuwen PWNM. Dalton Trans. 2003:1890.(b) Dierkes P, van Leeuwen PWNM. J Chem Soc, Dalton Trans. 1999:1519.(c) Shen Z, Dornan PK, Khan HA, Woo TK, Dong VM. J Am Chem Soc. 2009; 131:1077. [PubMed: 19128061] (d) Pawley RJ, Moxham GL, Dallanegra R, Chaplin AB, Brayshaw SK, Weller AS, Willis MC. Organometallics. 2010; 29:1717.

17.

Cyclohexene 7a arises from olefin-isomerization of $\mathbf{4 a}$.

18. Xie J-H, Zhou Q-L. Acc Chem Res. 2008; 41:581. [PubMed: 18311931]

19.

Aldehydes bearing substituted a-allyl groups such as crotyl, cinnamyl, and methallyl groups were unreactive with the Rh/SDP catalyst. We did not observe the desired cycloisomerization product in the reaction of an a,a-bis(homoallyl)aldehyde.

20.

Only some ligands promote this isomerization. DPPF and DPEphos were effective $(5 \% \mathrm{Rh} / \mathrm{L}, \mathrm{DCE}$,

$\left.40{ }^{\circ} \mathrm{C}\right) .(R)$-DTBM-SDP was less reactive even at higher catalyst loading $(10 \% \mathrm{Rh} / \mathrm{L})$.

21.

When D-labeled 4a $(\mathbf{4 a}-d)$ was subjected to the $\mathrm{Rh}^{+} /(\mathrm{R})$-DTBM-SDP catalyst (10 mol\%), we observed $70 \%$ conversion to $\mathbf{8}$ where the deuterium label was incorporated into the 4-position.

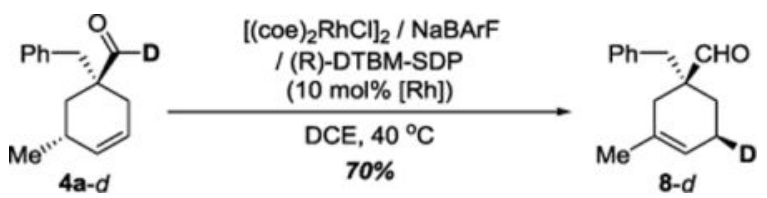

22. Lindgren BO, Nilsson T. Acta Chem Scand. 1973; 27:888.

23.

CCDC 1451888 contains the supplementary crystallographic data for compound $\mathbf{1 3}$. See Supporting Information. These data can be obtained free of charge via http://www.ccdc.cam.ac.uk/ data_request/cif, or by emailing data_request@ccdc.cam.ac.uk, or by contacting The Cambridge Crystallographic Data Centre, 879912, Union Road, Cambridge CB879952 879951EZ, UK; fax: +879944871223 336033 .

J Am Chem Soc. Author manuscript; available in PMC 2017 March 16. 
24. Paradine SM, Griffin JR, Zhao J, Petronico AL, Miller SM, White MC. Nature Chem. 2015; 7:987. [PubMed: 26587714] 

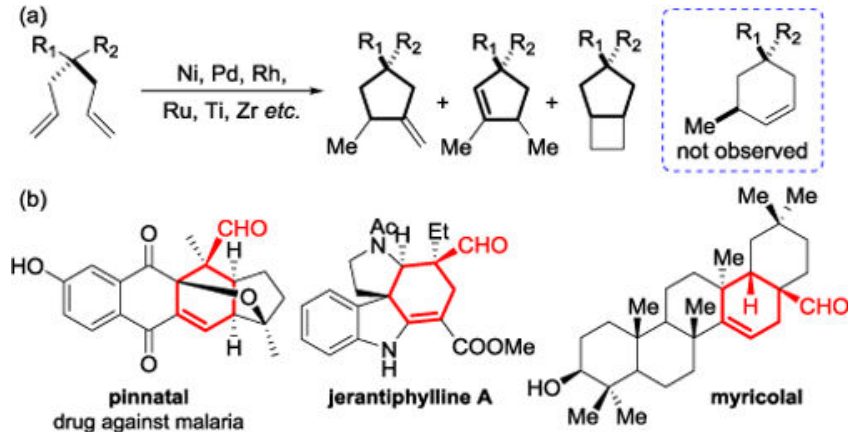

(c)

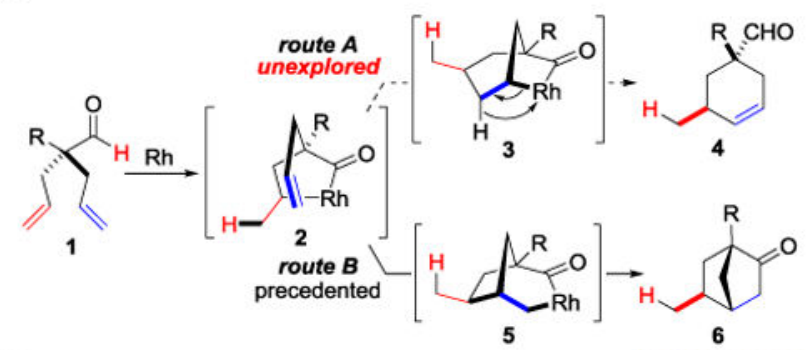

(d)

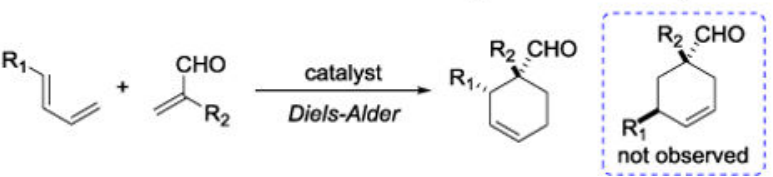

Figure 1.

Inspiration for $\mathrm{Rh}$-catalyzed cycloisomerization triggered by $\mathrm{C}-\mathrm{H}$ bond activation 
(a)

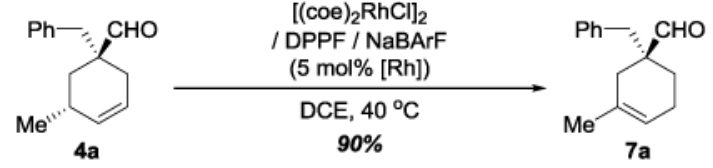

(b)

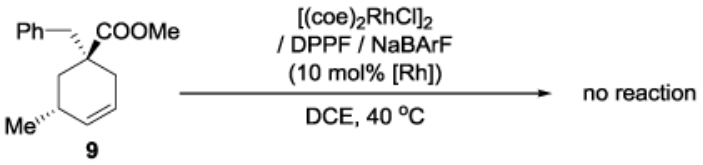

(c)

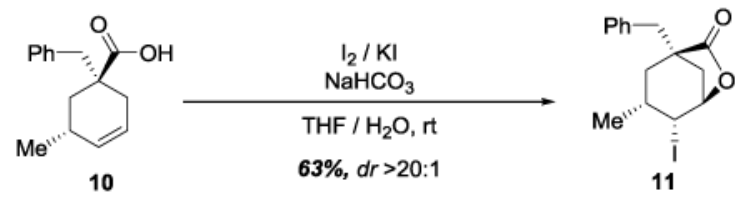

(d)

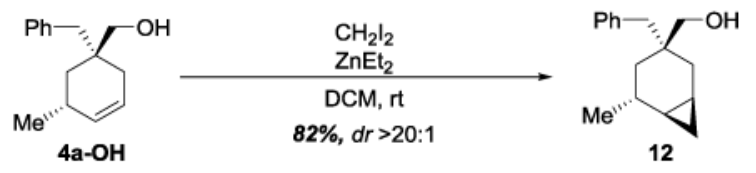

(e)

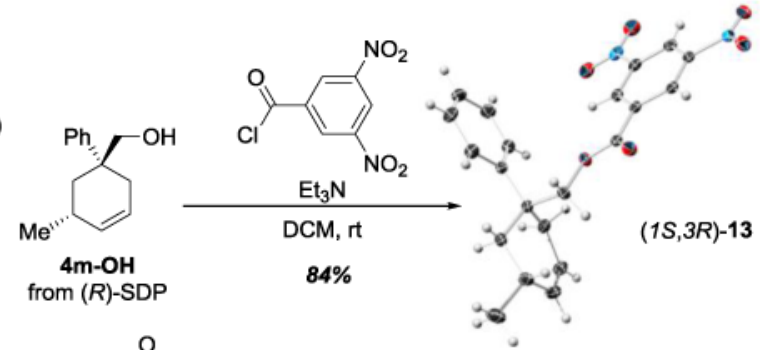

(f)

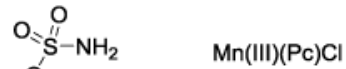

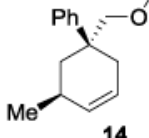

14
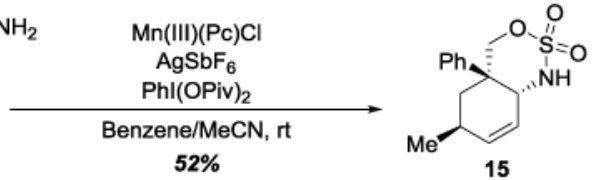

Scheme 1.

Elaboration of cyclohexenecarbaldehydes 


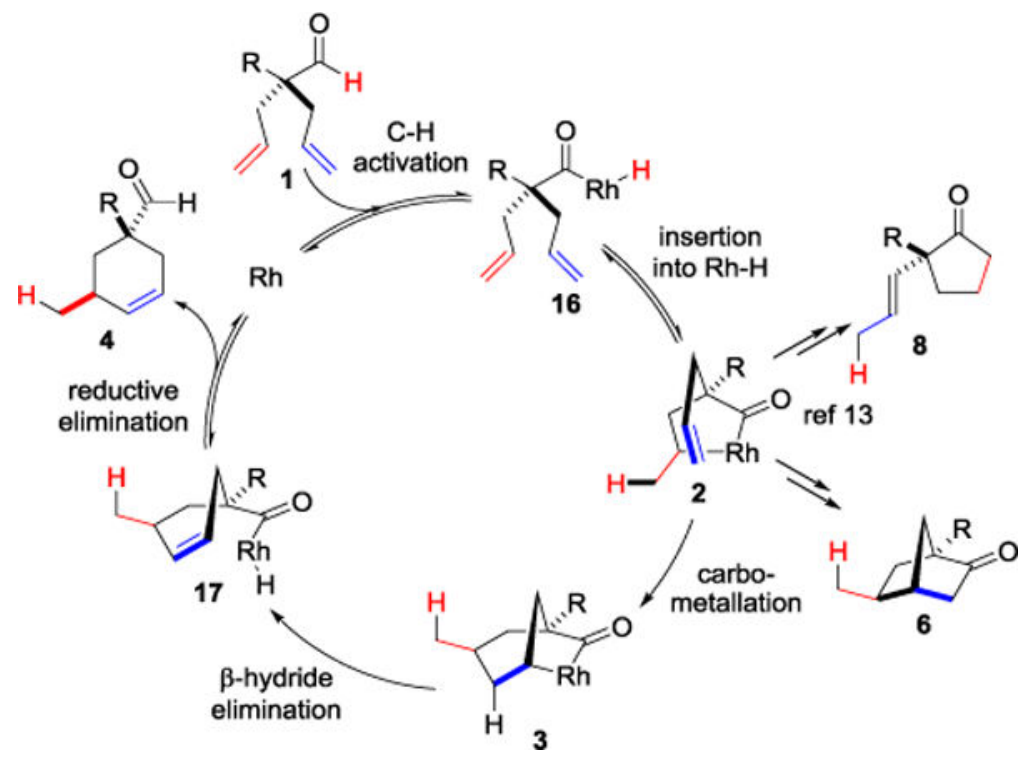

Scheme 2.

Proposed mechanism 

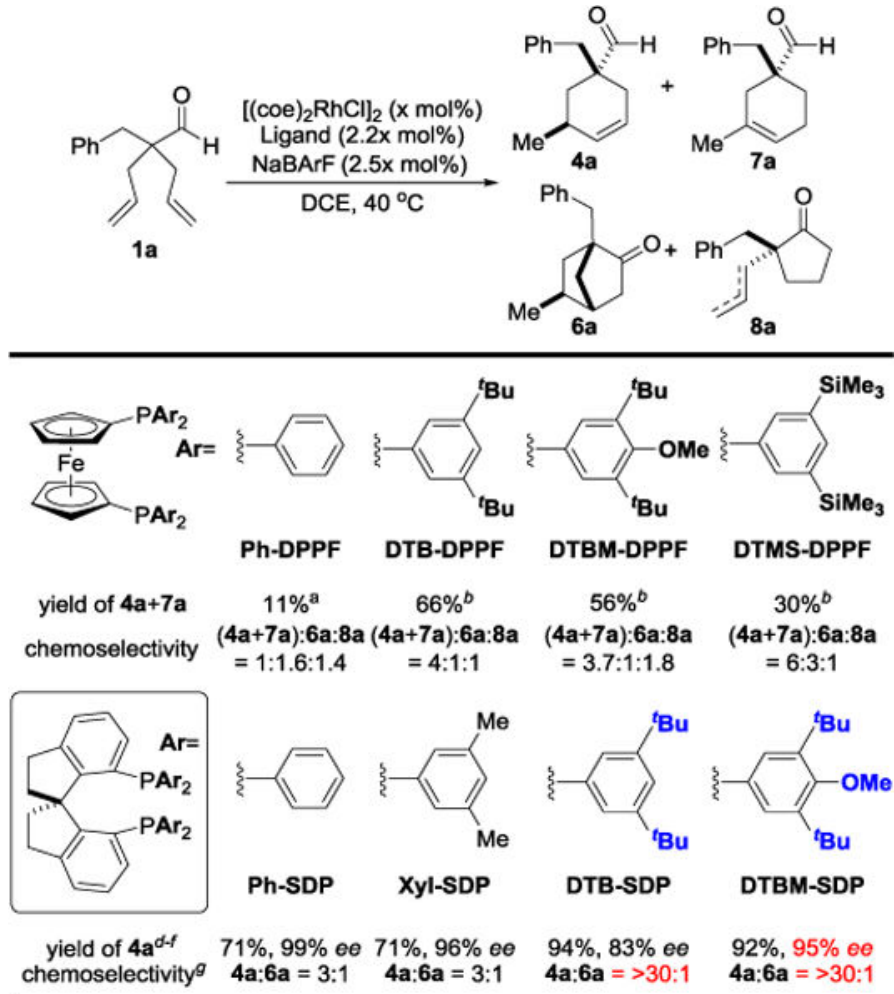

Chart 1. Ligand effects on the desymmetrization of a,a-bisallylaldehyde towards cyclohexenecarbaldehyde

${ }_{\mathrm{X}}^{a}=5,18$ h. ${ }^{b} \mathrm{X}=2.5,18$ h. ${ }^{c} \mathrm{X}=1.25,12$ h. ${ }^{e}>20: 1 d r$, determined by ${ }^{1} \mathrm{H}$ NMR. ${ }^{f}$ The aldehyde 4a was reduced to its corresponding alcohol to determine ee by SFC analysis with a chiral stationary phase. ${ }^{g}$ Trace amount of 7a and 8a was observed. Xyl: 3,5-Me-phenyl, DTB: 3,5di(t-butyl)-phenyl, DTBM: 3,5-di(t-butyl)-4-methoxy-phenyl, DTMS: 3,5-di(trimethylsilyl)phenyl. 


\section{Table 1}

Enantioselective cycloisomerization of a,a-bisallylaldehydes ${ }^{a}$

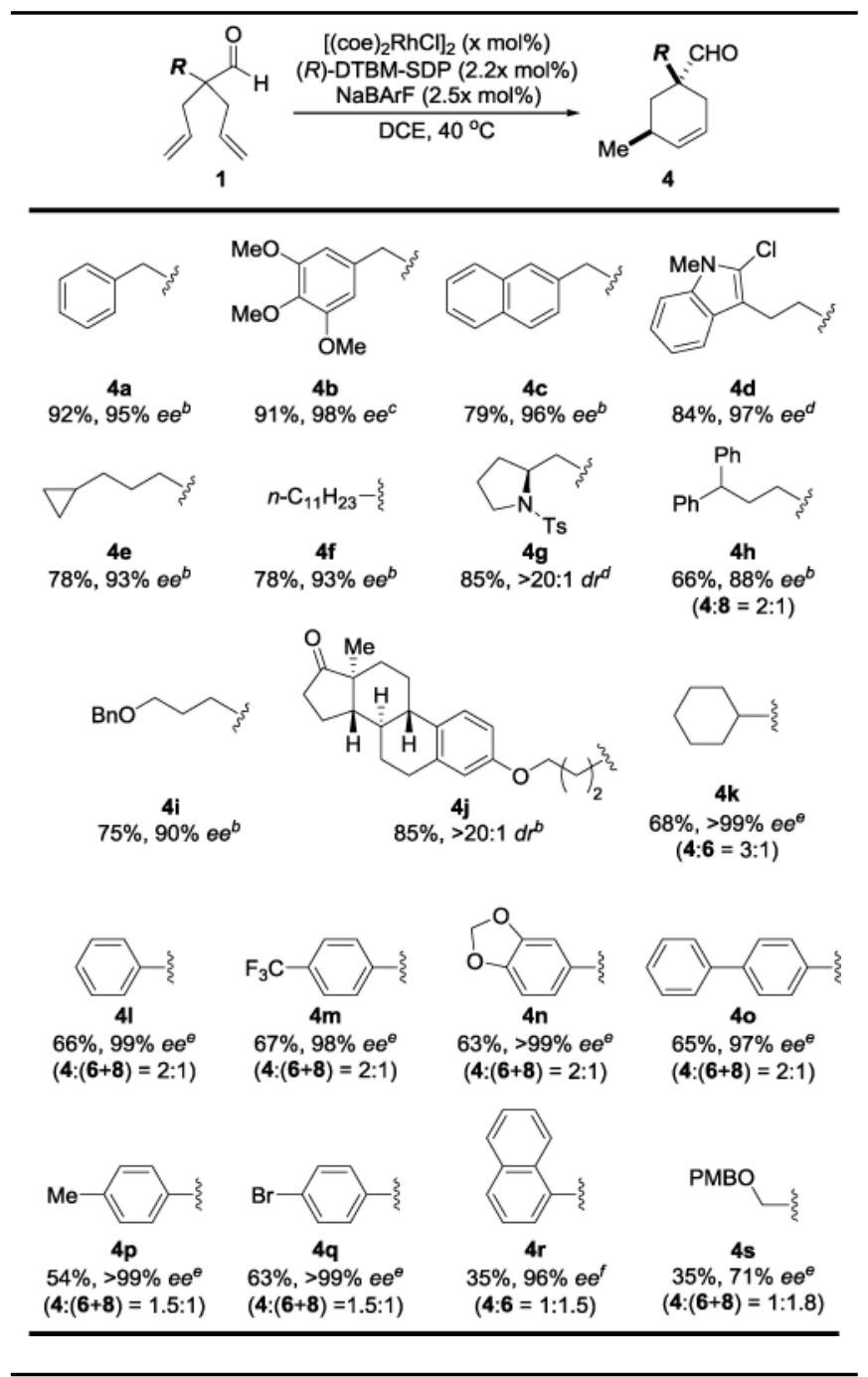

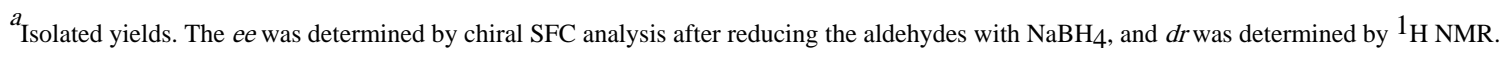

${ }^{b}$ Reaction condition: $\mathrm{x}=1.25,40^{\circ} \mathrm{C}, 4-12 \mathrm{~h}$.

$c_{\mathrm{x}=1, \mathrm{rt}, 2 \mathrm{~h} .}$

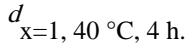

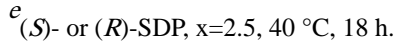

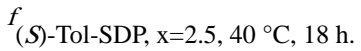

